\title{
Investigation of long period crustal deformation on the inactive branch of the North Anatolian Fault Zone
}

\author{
G. Akay ${ }^{1}$ and H. Ozener ${ }^{2,1}$ \\ ${ }^{1}$ Bogazici University, Kandilli Observatory and Earthquake Research Institute, Geodesy Department, Istanbul, Turkey \\ ${ }^{2}$ Istanbul Technical University, Civil Engineering Faculty, Department of Geodesy and Photogrammetry Engineering, \\ Istanbul, Turkey
}

Received: 12 September 2008 - Revised: 6 March 2009 - Accepted: 9 March 2009 - Published: 5 May 2009

\begin{abstract}
The western part of North Anatolian Fault (NAF) bifurcates around Mudurnu into two fault segments: northern and southern branch. The latter bifurcates again at west of Pamukova and creates middle strand. This study aimed to analyze crustal movement along the middle strand near Iznik which is considered as inactive fault. We focused on a microgeodetic network called General Command of MappingIstanbul Technical University (GCM-ITU) network around this segment. In order to obtain displacement values, five campaigns performed on the network which were used in the study. The displacements of the stations were estimated relative to the fixed stations located at the south of the network. The coordinates of the stations were calculated from the triangulation measurements realized in 1941 and 1963, trilateration measurements in 1981, and GPS campaigns in 2004 and 2007. Then, mean displacements of the network ranging between $7 \mathrm{~mm} / \mathrm{yr}$ and $18 \mathrm{~mm} / \mathrm{yr}$ were obtained for these years.

In the second part of the study, the GPS data were reprocessed by adding three stations from Marmara Continuous GPS Network (MAGNET). Details of MAGNET can be found Ergintav et al. (2002). Estimated displacements were ranging between $3 \mathrm{~mm} / \mathrm{yr}$ and $13 \mathrm{~mm} / \mathrm{yr}$ for 2004 and 2007 . TUBI station of IGS network was taken as stable.
\end{abstract}

\section{Introduction}

North Anatolian Fault Zone as the largest fault system of Anatolia is a natural junction between the Caucasus System and Aegean extension regime. North Anatolian Fault begins

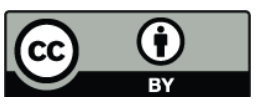

Correspondence to: $\mathrm{H}$. Ozener

(ozener@boun.edu.tr) from Karliova, elongates through whole Northern Anatolia until the vicinity of Mudurnu where bifurcated into IzmitSapanca Fault and Iznik-Mekece Fault (Fig. 1). The belt which is surrounded by these two faults form a middle strand which begins from Mudurnu Valley and goes through Geyve, Iznik, Gemlik and the southwest of the Marmara Region.

The Iznik-Mekece Fault that is located around west of Geyve, goes along approximately $15 \mathrm{~km}$ up to Sakarya as an right lateral fault (Barka, 1997) and then bounds the Geyve basin and then leaps over to the right side continuous through Mekece and Iznik Lake in W-SW direction. Many researches were conducted along the fault for investigating seismic potential (Stein et al., 1997; Barka and Reilinger, 1997; Reilinger et al., 2000, 2006; Ayhan et al., 2002; Ergintav et al., 2002, 2007; Meade et al., 2002; Ozener et al., 2009). The GCM-ITU network, that we focused, was established around Iznik region, and the points of network scattered along the middle strand. The study area and the stations are displayed in Fig. 2.

There were some evidence for large earthquakes occurred on Iznik-Mekece Fault in 29 AD (Guidoboni et al., 1994) and in $128 \mathrm{AD}$ (Ambraseys and Finkel, 1991). In addition to this, Stein et al. (1997) found a stress accumulation during 19391995 and evaluated $M>6.7$ earthquake probability as $12 \%$ during 1996-2026 along Iznik-Mekece Fault.

On the other hand, strong seismic events $(M>6)$ have not occurred on this fault nearly 200 years (Straub, 1996). Considering these studies mentioned above and own experiments, Barka (1997) suggested that the appearance interval of large events for Iznik area might have been around 2000 years or more. Thus, the fault is claimed as inactive in general. Figure 3 shows the seismicity of the region.

Geodesy Department of Kandilli Observatory and Earthquake Research Institute (KOERI) started crustal deformation studies on the Iznik region. Between 1990 and 1994, the

Published by Copernicus Publications on behalf of the European Geosciences Union. 


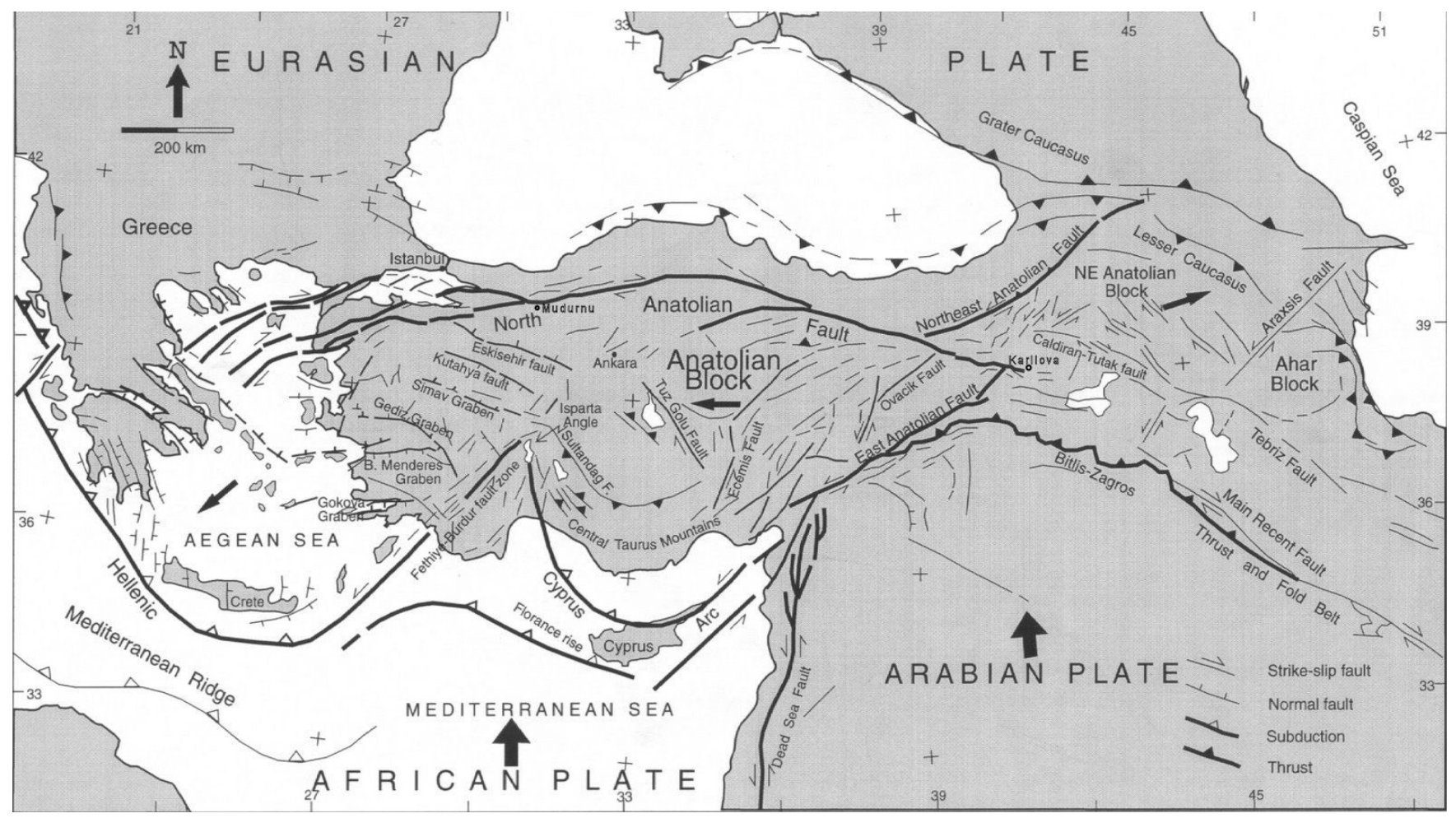

Fig. 1. The tectonic map of Turkey (modified from Barka and Reilinger, 1997).

terrestrial measurements and from 1994 several GPS campaigns were conducted in the vicinity of Iznik-Mekece Fault (Gurkan et al., 1999, 2001; Ozener, 2000; Akay, 2007). The mean velocity of Iznik-Mekece segment was found $18 \mathrm{~mm} / \mathrm{yr}$ for the 1994-1998 period (Ozener, 2000). The estimated GPS displacement during the first 298 postseismic days after the Izmit Earthquake (17 August 1999, $M_{w}=7.4$ ) for IGAZ station around the fault (Ergintav et al., 2002) was approximately $85 \mathrm{~mm}$ in direction of southwest.

The GCM-ITU network was originally implemented by GCM and measured with conventional techniques in 1941, 1963 and 1981. In 1941 and 1963, the network observed with triangulation method by GCM. These observations actually conducted to connect the stations to the national triangulation network. In 1981, the network was re-observed by Geodesy Department of ITU applying angle and distance measurements. The slope distances were observed by tellurometer, and then reduced to sea level.

After twenty years, the network became a part of the microgeodetic networks of Geodesy Department of KOERI. It was designated to monitor crustal deformation around the western part of NAFZ. In 2004 and 2007, two GPS campaigns were performed on the network.

In addition to this, the study area was extended by adding new stations from MAGNET. This extended network helped us to find the displacements of all points of GCM-ITU network relative to TUBI station of MAGNET.
By this study, both terrestrial and GPS campaign data sets for a long time period along Iznik-Mekece Fault is presented for the first time.

\section{Method for the data analysis}

The composition of network geometry had been changed for each campaign. Some of the network stations were not implemented before 1981 and some of them damaged in years. The network stations and the campaign dates are shown in Table 1.

While calculating displacements, the data analyzed into two steps. First, the terrestrial data were processed and analyzed. The inadequate number of control stations to transform one coordinate system to another led us to analyze the all GPS data as if they had been observed by conventional methods. Therefore, GPS baseline results were employed as a trilateration network set into the network adjustment for the first step.

In order to have adjusted coordinates for each observation

- A single free network adjustment per epoch,

- A single constrained adjustment according to reference stations,

. The estimation of horizontal displacements, 


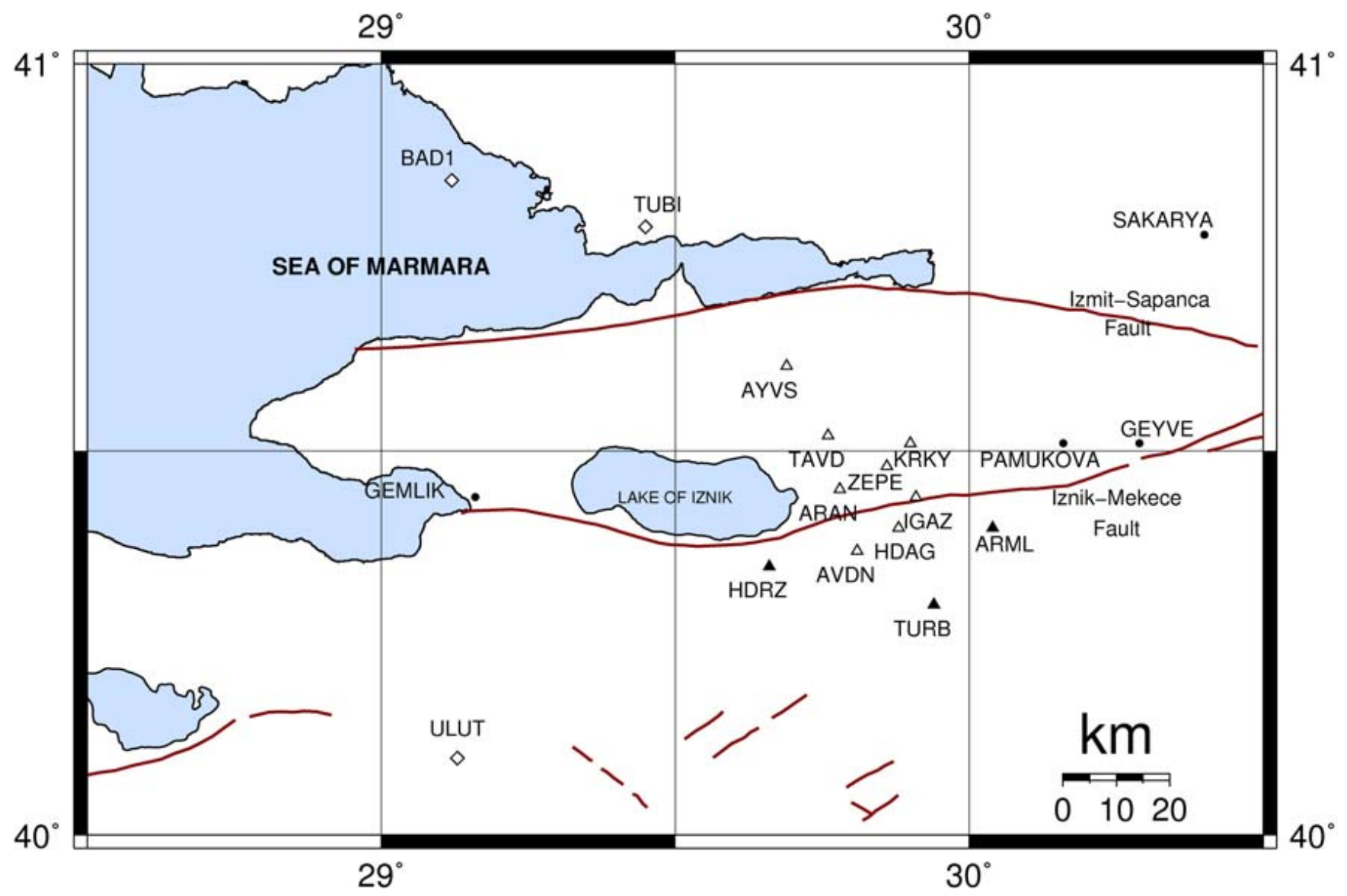

Fig. 2. Study area and the stations. Stations shown by the triangles are the stations of the GCM-ITU Network. The filled triangles are the fixed stations and the empty ones are tied stations. The diamond symbols show the stations of MAGNET.

- Comparison of displacements and their analysis were computed.

The GPS data were processed individually in the second part of the study for GCM-ITU network and the extended network. Therefore, we were able to obtain more recent information about movement around the Iznik-Mekece Fault.

In order to compare the displacements, the stations HDRZ, ARML, and TURB were taken as fixed; so the concept of the adjustment method was based on the idea of having sufficient number of stations located one side of the Iznik-Mekece Fault. As a result, we could determine the relative motions of remaining stations. Control stations also served as datum definition in the study.

\subsection{The analysis between 1981 and 2007 by terrestrial measurements}

Prior to the development of electronic distance measuring equipments and the global positioning system, triangulation was the preferred method for extending horizontal control over long distances. In 1941 and 1963, the GCM-ITU network was monitored by triangulation method. Nevertheless
Table 1. The network stations and the available data in the campaign dates.

\begin{tabular}{lccc}
\hline Stations ID & $1941 / 1963$ & 1981 & 2004-2007 \\
\hline ARML & + & + & + \\
AVDN & + & + & \\
AYVS & + & & \\
ARAN & & + & + \\
IGAZ & & & + \\
HDAG & & + & + \\
HDRZ & + & + & + \\
KRKY & + & + & \\
TAVD & + & + & + \\
TURB & + & + & + \\
ZEPE & & + & \\
\hline
\end{tabular}

both measurements did not contain adequate number of observations for network adjustment. Furthermore, they also failed individually to form proper geometry. Therefore, it was decided to combine both measurements and adjust them 


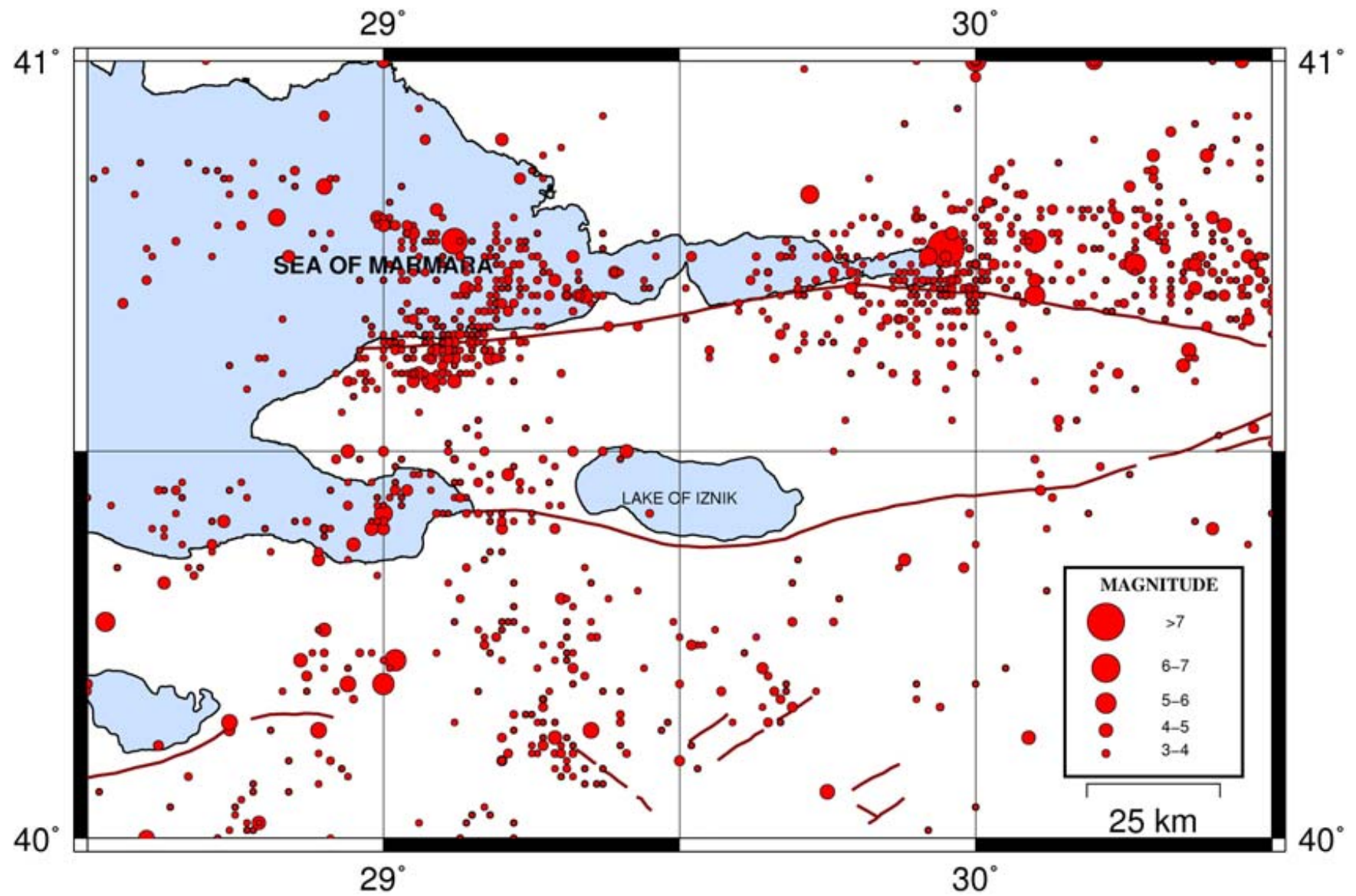

Fig. 3. Seismicity of the region. Seismic data (between 1900 and 2007) is obtained from National Earthquake Monitoring Center of KOERI.

as a single observation. In adjustment process, a program using least squares, written in FORTRAN, was applied.

However, the insufficient geometry of networks had a misleading influence on results and mean square errors were obtained more than $350 \mathrm{~mm}$. Consequently, the 1941 and 1963 observations could not be used in displacement analysis.

In 1981, both trilateration and triangulation methods were applied. Baselines were measured by one of the first generation EDM systems: the tellurometer. Horizontal distances were produced from the raw slope distances by using the reduction to sea level formulas:

$S_{0}=\left[\frac{S_{a}-\left(H_{2}^{2}-H_{1}^{2}\right)}{\left(1+\frac{H_{1}}{R_{\alpha}}\right)\left(1+\frac{H_{2}}{R_{\alpha}}\right)}\right]^{1 / 2}+\frac{S_{E}^{3}}{24 R_{\alpha}^{2}}$

where $S_{a}$ is the slope distance, $H_{1}$ and $H_{2}$ are the ellipsoidal heights, $R_{\alpha}$ is the Gauss sphere radius, $S_{E}$ is the ellipsoidal distance, and $S_{0}$ is the horizontal distance. Changes in the coordinates of TAVD, ARAN and HDAG stations were evaluated using constrained adjustment relative to the fixed stations (HDRZ, ARML, TURB). Apart from these, the number of redundant observations was adequate in 1981 survey to apply free network adjustment in order to check outliers.
The Pope test which applies a posteriori variances was used upon observations in order to check outliers and determine the confidence regions.

Standardized correction for Pope Test was found 3.106. Thus, the observations whose errors exceed that correction limit were eliminated. The maximum positioning error was $\operatorname{mp}_{\max }= \pm 140 \mathrm{~mm}$.

The GPS measurements were carried out in 2004 and 2007 using campaign method. Trimble Geomatics Office Software (TGO, 2007) was employed to process GPS data using precise orbits gathered from International Global Navigation Satellite Systems Service (IGS, 2007) web site. Constrained adjustment applied to only one control station, which was held fixed in the survey network and was employed to evaluate GPS measurements. In order to compare the terrestrial data to the GPS outcomes, baseline components were separated from coordinate results and designating as raw data and then processed again individually as trilateration measurements by constrained adjustment relative to fixed stations (HDRZ, ARML, TURB) in ED-50 datum. Apart from the individual adjustment of each campaign, we combined them and used as a single trilateration network in free network adjustment in order to increase the degrees of freedom. 


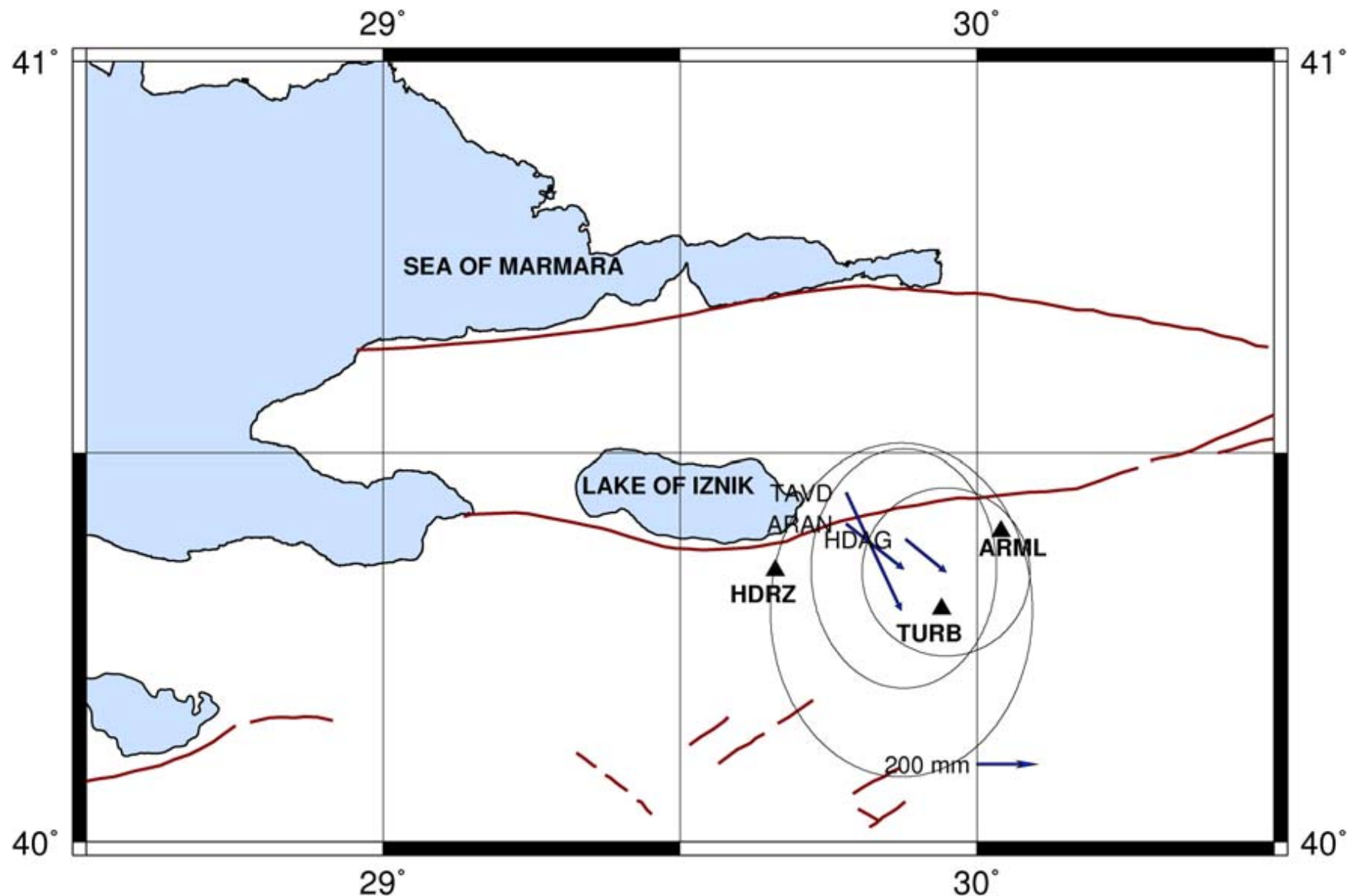

Fig. 4. The amount of displacements between 1981 and 2004-2007. The displacements of TAVD, ARAN, and HDAG stations were estimated relative to the fixed stations (TURB, HDRZ, and ARML) located in the Anatolian plate.

Table 2. Station List and Estimated Displacements between 1981 and 2004-2007 in ED-50 Datum. The displacements of TAVD, ARAN and HDAG stations were estimated relative to the fixed stations (TURB, HDRZ, ARML) located in the Anatolian plate.

\begin{tabular}{lllllllll}
\hline Station & \multicolumn{2}{l}{ Station coordinates } & \multicolumn{2}{l}{ Observation periods } & \multicolumn{2}{c}{ Displacements } & \multicolumn{2}{c}{ Uncertainties } \\
ID & Latitude & Longitude & First & Last & North mm & East mm & dn mm & de mm \\
\hline TAVD & 40.522 & 29.7574 & 1981 & $2004-2007$ & -391 & 183 & 89 & 113.8 \\
ARAN & 40.4472 & 29.7782 & 1981 & $2004-2007$ & -150 & 191 & 63 & 81 \\
HDAG & 40.3992 & 29.8826 & 1981 & $2004-2007$ & -109 & 134 & 57 & 62 \\
TURB & 40.2988 & 29.9421 & 1981 & $2004-2007$ & - & - & - & - \\
HDRZ & 40.3512 & 29.6638 & 1981 & $2004-2007$ & - & - & - & - \\
ARML & 40.3969 & 30.0394 & 1981 & $2004-2007$ & - & - & - & - \\
\hline
\end{tabular}

Afterwards, the Two Dimensional Helmert Transformation was applied to coordinates obtained from free network adjustment of combined 2004 and 2007 GPS data. Then, displacements were investigated between the outputs of TAVD, ARAN and HDAG stations from the network adjustment results of 1981 and of combined GPS campaign of 2004 and 2007. Each component of the coordinates and the directions of the displacement vectors are shown in the Table 2 as well as in Fig. 4.

\subsection{The analysis between 2004 and 2007 by GPS measurements}

Geodetic observations were repeated on GCM-ITU Network in 2004 and 2007 using GPS technique by Geodesy Department of KOERI. However, only six of the stations could survive to this time. IGAZ station was added to network, in order to densify the northern part. 


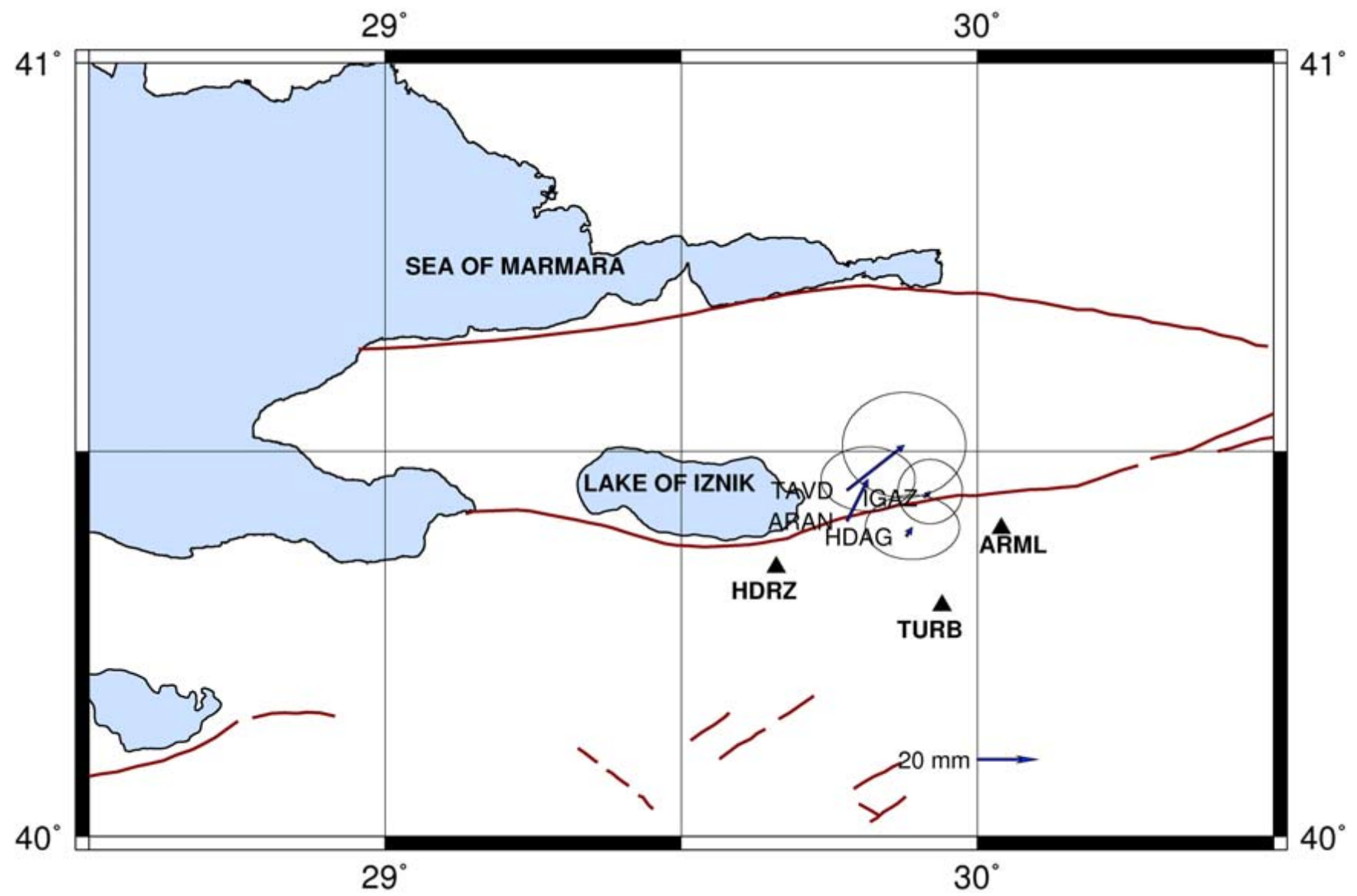

Fig. 5. The amount of displacements between 2004 and 2007. The displacements of TAVD, ARAN, HDAG, and IGAZ stations were estimated relative to the fixed stations (TURB, HDRZ, and ARML) located in the Anatolian plate.

Table 3. Station List and Estimated Displacements between 2004 and 2007 in WGS-84 Datum. The displacements of TAVD, ARAN and HDAG stations were estimated relative to the fixed stations (TURB, HDRZ, ARML) located in the Anatolian plate.

\begin{tabular}{lllllllll}
\hline \multirow{2}{*}{$\begin{array}{l}\text { Stations } \\
\text { ID }\end{array}$} & \multicolumn{2}{l}{ Station coordinates } & \multicolumn{2}{l}{ Observation periods } & \multicolumn{2}{l}{ Displacements } & \multicolumn{2}{l}{ Uncertainties } \\
& Latitude & Longitude & First & Last & North mm & East mm & dn mm & de mm \\
\hline TAVD & 40.521 & 29.7569 & 2004.32 & 2007.122 & 15 & 19 & 4.2 & 3.6 \\
ARAN & 40.4462 & 29.7778 & 2004.32 & 2007.122 & 14 & 7 & 3.2 & 2.2 \\
HDAG & 40.3982 & 29.8822 & 2004.32 & 2007.122 & 3 & 1 & 3.2 & 2.2 \\
IGAZ & 40.438 & 29.908 & 2004.32 & 2007.122 & 2 & 2 & 2.2 & 2.2 \\
TURB & 40.2978 & 29.9417 & 2004.32 & 2007.122 & - & - & - & - \\
HDRZ & 40.3511 & 29.6634 & 2004.32 & 2007.122 & - & - & - & - \\
ARML & 40.3959 & 30.039 & 2004.32 & 2007.122 & - & - & - & - \\
\hline
\end{tabular}

The method of static GPS measurement was performed in this study. Therefore the campaigns had been planned to monitor the network at least $8 \mathrm{~h}$ with $15 \mathrm{~s}$ logging interval, but some environmental problems lessen that time.

TGO and GPS Inferred Positioning System/Orbit Analysis and Simulation Software (GIPSY/OASIS II) from JPL (Webb and Zumberge, 1993; Gregorius, 1996) were used in GPS processing.
First, precise coordinates of stable stations were evaluated using precise point positioning (PPP) method in GIPSY/OASIS II. Then, constrained adjustment option in TGO was employed. The analysis strategy was similar to the previous section in order to compare the outcomes. Changes on northing and easting coordinates for each tied stations (HDAG, ARAN, TAVD, ARML, IGAZ) were investigated according to the significance and direction of movement. 


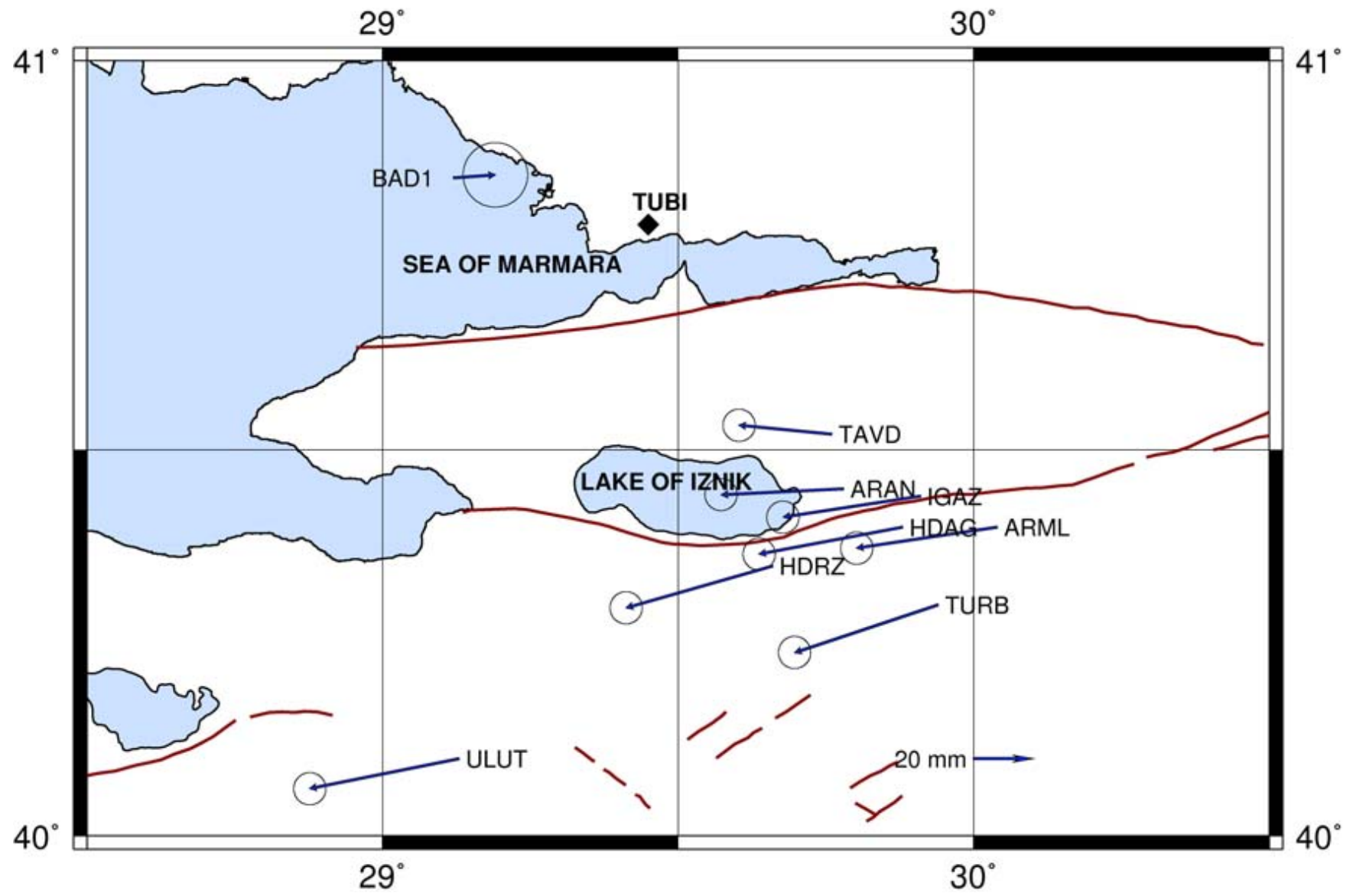

Fig. 6. The amount of displacement between 2004 and 2007 on the extended network. The network is analyzed relative to TUBI station.

Table 4. Station List and Estimated Displacements between 2004 and 2007 in WGS-84 Datum. The displacements of the stations were estimated relative to the TUBI station.

\begin{tabular}{|c|c|c|c|c|c|c|c|c|}
\hline \multirow{2}{*}{$\begin{array}{l}\text { Stations } \\
\text { ID }\end{array}$} & \multicolumn{2}{|c|}{ Station coordinates } & \multicolumn{2}{|c|}{ Observation periods } & \multicolumn{2}{|c|}{ Displacements } & \multicolumn{2}{|c|}{ Uncertainties } \\
\hline & Latitude & Longitude & First & Last & North mm & East mm & $\begin{array}{l}\mathrm{dn} \\
\mathrm{mm}\end{array}$ & $\begin{array}{l}\mathrm{de} \\
\mathrm{mm}\end{array}$ \\
\hline TAVD & 40.521 & 29.7569 & 2004.32 & 2007.122 & 3 & -31 & 1.14 & 1.14 \\
\hline ARAN & 40.4462 & 29.7778 & 2004.32 & 2007.122 & -2 & -41 & 1.14 & 1.14 \\
\hline HDAG & 40.3982 & 29.8822 & 2004.32 & 2007.122 & -9 & -48 & 1.14 & 1.14 \\
\hline IGAZ & 40.438 & 29.908 & 2004.32 & 2007.122 & -7 & -46 & 1.14 & 1.14 \\
\hline TURB & 40.2978 & 29.9417 & 2004.32 & 2007.122 & -16 & -48 & 1.14 & 1.14 \\
\hline HDRZ & 40.3511 & 29.6634 & 2004.32 & 2007.122 & -14 & -49 & 1.14 & 1.14 \\
\hline ARML & 40.3959 & 30.039 & 2004.32 & 2007.122 & -7 & -47 & 1.14 & 1.14 \\
\hline ULUT & 40.0975 & 29.1314 & 2004.32 & 2007.122 & -10 & -50 & 1.14 & 1.14 \\
\hline BAD1 & 40.8512 & 29.1179 & 2004.32 & 2007.122 & 1 & 14 & 2.23 & 2.23 \\
\hline TUBI & 40.7867 & 29.4507 & 2004.32 & 2007.122 & - & - & - & - \\
\hline
\end{tabular}

Changes on northing and easting coordinates between 2004 and 2007 are shown in Table 3. The largest movement is found in TAVD which is the furthest station from the Iznik-Mekece Fault. Accordingly, the minimum movement is found in HDAG, which is the nearest station to the fault.
As displayed on Fig. 5, the direction of movements is different from the terrestrial observation results and all stations are oriented to northeast relative to fixed stations (HDRZ, ARML, TURB) located in Anatolian plate. 


\subsubsection{The analysis between 2004 and 2007 on the extended network}

In order to investigate other effects on GCM-ITU network rather than the Iznik-Mekece Fault and to extend the research area, three stations from MAGNET, conducted by The Scientific and Technical Research Council of Turkey (TUBITAK) - Marmara Research Center (MRC) - Earth and Marine Sciences Research Institute (EMSRI), were used in the study. While selecting the stations from MAGNET, the locations of the stations and the data availability for the day of the campaigns were taken into consideration. In this part, deformations are estimated with the contribution of three MAGNET stations: BAD1, TUBI and ULUT.

TGO software was also employed for GPS processing step of the extended network. Although, the process method was same, the adjustment model was different from previous one, because of the fact that tying the network to MAGNET stations would result in more precise outcomes. TUBI station was selected as the fixed station and the precise coordinates of TUBI station were obtained from Scripps Orbit and Permanent Array Center (SOPAC, 2007) web site on the Internet in connection with the exact day of the observations. Then, minimally constrained adjustment was applied to the data. The GPS stations, the displacement values between 2004 and 2007 and occupation times are shown in Table 4; the displacement values are shown in Fig. 6 .

\section{Results and discussion}

There were three analysis conducted on the GCM-ITU network in the study. Results of both GPS and terrestrial observations revealed that, the stations at the both side of the fault have moved to almost the same direction during for the 1941-2007 period.

In the first part of the study, the terrestrial data and baselines obtained from GPS observations are analyzed by least squares adjustment method. The displacement values were estimated $431 \mathrm{~mm}$ for TAVD station, $243 \mathrm{~mm}$ for ARAN station and $173 \mathrm{~mm}$ for HDAG station between 1981 and 2004-2007 (accepted as 2005.5 epoch). Therefore, mean displacements ranging between $7 \mathrm{~mm} / \mathrm{yr}$ and $18 \mathrm{~mm} / \mathrm{yr}$ were obtained for 24.5 years (1981-2005.5). In an earlier study, the horizontal velocity of Iznik network of KOERI had been found $18 \mathrm{~mm} / \mathrm{yr}$ for the $1994-1999$ period before the Izmit Earthquake (17 August 1999, $M_{w}=7.4$ ) from GPS observations (Ozener, 2000). In addition to this, $18.09 \mathrm{~mm} / \mathrm{yr}$ was found for IGAZ station between 1994.7 and 1996.8 epochs in the study of McClusky et al. (2000). Both studies are consistent with our outcomes. As it shown in Fig. 4, the TAVD and ARAN stations move to the southeast relative to fixed stations (HDRZ, ARML, TURB) located in Anatolian plate. Contrarily, the HDAG station moves within the same direction, even though the location of the station relative to the fault is different from others.

In the second part of the study, the GPS data were studied. The deformation investigated again relative to fixed stations (HDRZ, ARML, TURB) located in Anatolian plate. However, the stations were directed to northeast which was different from the terrestrial ones. The changes in direction of displacement vectors can be caused by the two successive earthquakes (17 August 1999, $M_{w}=7.4$, Izmit and 12 November 1999, $M_{w}=7.2$, Duzce) which may shift the whole datum of the network. The displacement values were estimated $24.2 \mathrm{~mm}$ for TAVD station, $15.7 \mathrm{~mm}$ for ARAN station, $3.16 \mathrm{~mm}$ for HDAG station and $2 \mathrm{~mm}$ for IGAZ station between 2004 and 2007.

Furthermore, in the extended network, the GCM-ITU network moves to the west relative to TUBI station for the 20042007 period. Ergintav et al. (2007) conducted a study on the Marmara region between 2003 and 2005. The velocity rates of IGAZ and ULUT stations, which were consistent with our results in Table 3, were obtained as $23.50 \mathrm{~mm} / \mathrm{yr}$ and $23.17 \mathrm{~mm} / \mathrm{yr}$ relative to the Eurasian-fixed reference frame in the study.

Based on the velocity differences (Fig. 6) on the north and south of Iznik-Mekece fault, we can conclude that, there is not any strain accumulation in the region which results basically no tectonic activity. In addition, this region has low seismic activity (Fig. 3). Hence, this fault is still inactive as claimed in Barka's earlier studies.

Acknowledgements. The authors gratefully acknowledge of the cooperation and help of Rasim Deniz who provided us the terrestrial data. Thanks go to Ugur Sanli, and Cihangir Ozsamli for their valuable comments on data analysis. Thanks are due also to our colleagues at TUBITAK-MRC-EMSRI, particularly Semih Ergintav for providing us the GPS data. The authors wish to thank the reviewers for their constructive comments. The authors would also like to thank the Jet Propulsion Laboratory of the California Institute of Technology for allowing us to use GIPSY/OASIS II software, and the Trimble Navigation Limited for TGO software. The maps were made using the GMT software (Wessel and Smith, 1995).

Edited by: M. Contadakis

Reviewed by: an anonymous referee

\section{References}

Akay, G.: Analysis of Total Crustal Deformation by the Comparison of Terrestrial and GPS Measurements in the Marmara Region, M. S. thesis, Bogazici University, Istanbul, Turkey, 92 pp., 2007.

Ambraseys, N. N. and Finkel, C. F.: Long-term seismicity of Istanbul and of the Marmara sea region, Terra Nova, 3, 527-539, 1991.

Ayhan, M. E., Demir, C., Lenk, O., Kiliçoglu, A., Altiner, Y., Barka, A. A., Ergintav, S., and Ozener, H.: Interseismic strain accu- 
mulation in the Marmara sea region, B. Seismol. Soc. Am., 92, 216-229, 2002.

Barka, A.: Neotectonics of the Marmara region, Active tectonics of Northwestern Anatolia-the Marmara poly-project, A multidisciplinary approach by space-geodesy, geology, hydrogeology, geotermics and seismology, vdf Hochschulverlag AG an der ETH, Zurich, 55-87, 1997

Barka, A. and Reilinger, R.: Active tectonics of the Eastern Mediterranean region: deduced from GPS, neotectonic and seismicity data, Ann. Geophys.-Italy, XL, 1997.

Ergintav, S., Burgmann, R., McClusky, S., Cakmak, R., Reilinger, R. E., Lenk, O., Barka, A., and Ozener H.: Postseismic deformation near the Izmit earthquake (17 August 1999, M 7.5) rupture zone, B. Seismol. Soc. Am., 92, 194-207, 2002.

Ergintav, S., Dogan, U., Gerstenecker, C., Cakmak, R., Belgen, A., Demirel, H., Aydin, C., and Reilinger, R.: A snapshot (20032005) of the 3D postseismic deformation for the 1999, $M_{w}=7.4$ Izmit earthquake in the Marmara Region, Turkey, by first results of joint gravity and GPS monitoring, J. Geodyn., 44, 1-18, 2007.

Gregorius, T.: GIPSY-OASIS II: How It Works, Department of Geomatics, University of Newcastle upon Tyne, University of Newcastle, UK, 149 pp., 1996.

Guidoboni, E., Comastri, A., and Traina, G.: Catalogue of Ancient Earthquakes in Mediterranean Area up to the 10th Century, Istituto Nazionale di Geofisica, Bologna, Italy, 504 pp., 1994.

Gurkan, O., Igdir, I., Ozener, H., Sakalli, Y., Turgut, B., and Yilmaz, O.: Results of GPS measurements for networks designed for terrestrial observations, in the Western part of NAFZ, in: Proceedings of the Third Turkish-German Joint Geodetic Days, Istanbul, Turkey, 932-935, 1-4 June 1999.

Gurkan O., Ozener, H., Yilmaz, O., and Turgut, B.: Results of post seismic GPS measurements related to Izmit earthquake (August 17, 1999), in: Proceedings of the Fourth Turkish-German Joint Geodetic Days, Berlin, Germany, 77-83, 3-6 April 2001.

International GNSS Service: http://igscb.jpl.nasa.gov/, last access: 20 May 2007.

McClusky, S., Balassanian, S., Barka, A., Demir, C. Ergintav S., Georgiev, I., Gurkan, O., Hamburger, M., Hurst, K., Kahle, H., Kastens, K., Kekelidze, G., King, R., Kotzev, V., Lenk, O., Mahmoud, S., Mishin, A., Nadariya, M., Ouzounis, A., Paradissis, D., Peter, Y., Prilepin, M., Reilinger, R., Sanli, I, Seeger, H., Tealeb, A., Toksoz, M. N., and Veis, G.: Global Positioning System constraints on plate kinematics and dynamics in the eastern Mediterranean and Caucasus, J. Geophys. Res., 105, 5695-5720, 2000 .
Meade, B. J., Hager, B. H., McClusky, S. C., Reilinger, R. E., Ergintav, S., Lenk, O., Barka, A., and Ozener, H.: Estimates of seismic potential in the Marmara sea region from block models of secular deformation constrained by Global Positioning System measurements, B. Seismol. Soc. Am., 92, 208-215, 2002.

Ozener, H.: Monitoring Regional Horizontal Crustal Movements by Individual Microgeodetic Networks Established Along Boundaries, Ph.D. thesis, Bogazici University, Istanbul, Turkey, 89 pp., 2000.

Ozener, H., Dogru, A., and Unlutepe, A.: An approach for rapid assessment of seismic hazards in Turkey by continuous GPS data, Sensors, 9(1), 602-615, 2009.

Reilinger, R. E., Ergintav, S., Burgmann, R., McClusky, S., Lenk, O., Barka, A., Gurkan, O., Hearn, L., Feigl, K. L., Cakmak, R., Aktug, B., Ozener, H., and Toksoz, M. N.: Coseismic and postseismic fault slip for the 17 August, 1999, M=7.5, Izmit, Turkey earthquake, Science 289, 1519-1524, 2000.

Reilinger, R., McClusky, S., Vernant, P., Lawrance, S., Ergintav, S., Cakmak, R., Ozener, H., Kadirov, F., Guliev, I., Stepanyan, R., Nadariya, M., Hahubia, G., Mahmoud, S., Sakr, K., ArRajehi, A., Paradissis, D., Al-Aydrus, A., Prilepin, M., Guseva, T., Evren, E., Dmitrotsa, A., Filikov, S. V., Gomez, F., Al-Ghazzi, R., and Karam, G.: GPS constraints on continental deformation in the Africa-Arabia-Eurasia continental collision zone and implications for the dynamics of plate interactions, J. Geophys. Res., 111, B05411, doi:10.1029/2005JB004051, 2006.

SOPAC: http://sopac.ucsd.edu/processing/coordinates, last access: 20 May 2007.

Straub, C.: Recent Crustal Deformation and Strain Accumulation in the Marmara Sea Region, N. W. Anatolia, Inferred from GPS Measurements, Ph.D. thesis, ETH, Zurich Switzerland, 123 pp, 1996.

Stein, R. S., Barka, A. A., and Dieterich, J. H.: Progressive failure on the North Anatolian fault since 1939 by earthquake stress triggering, Geophys. J. Int., 128, 594-604, 1997.

Trimble Geomatics Office: http://www.trimble.com/ geomaticsoffice.shtml, last access: 15 April 2007.

Webb, F. H. and Zumberge, J. F.: An Introduction to GIPSY/OASIS II, JPL Publ., D-11088, Jet Propulsion Laboratory, Pasadena, California, 1993.

Wessel, P. and Smith, W. H. F.: The Generic Mapping Tools (GMT) Version 3.4 Technical Reference \& Cookbook, SOEST/NOAA, 2001. 